\title{
Effect of Removal of Planned Parenthood from the Texas Women's Health Program
}

\author{
Amanda J. Stevenson, M.A., Imelda M. Flores-Vazquez, Ph.D., \\ Richard L. Allgeyer, Ph.D., Pete Schenkkan, J.D., and Joseph E. Potter, Ph.D.
}

A BSTRACT

BACKGROUND

Texas is one of several states that have barred Planned Parenthood affiliates from providing health care services with the use of public funds. After the federal government refused to allow (and courts blocked) the exclusion of Planned Parenthood affiliates from the Texas Medicaid fee-for-service family-planning program, Texas excluded them from a state-funded replacement program, effective January 1, 2013. We assessed rates of contraceptive-method provision, method continuation through the program, and childbirth covered by Medicaid before and after the Planned Parenthood exclusion.

\section{METHODS}

We used all program claims from 2011 through 2014 to examine changes in the number of claims for contraceptives according to method for 2 years before and 2 years after the exclusion. Among women using injectable contraceptives at baseline, we observed rates of contraceptive continuation through the program and of childbirth covered by Medicaid. We used the difference-in-differences method to compare outcomes in counties with Planned Parenthood affiliates with outcomes in those without such affiliates.

\section{RESULTS}

After the Planned Parenthood exclusion, there were estimated reductions in the number of claims from 1042 to 672 (relative reduction, 35.5\%) for long-acting, reversible contraceptives and from 6832 to 4708 (relative reduction, 31.1\%) for injectable contraceptives ( $\mathrm{P}<0.001$ for both comparisons). There was no significant change in the number of claims for short-acting hormonal contraceptive methods during this period. Among women using injectable contraceptives, the percentage of women who returned for a subsequent on-time contraceptive injection decreased from 56.9\% among those whose subsequent injections were due before the exclusion to $37.7 \%$ among those whose subsequent injections were due after the exclusion in the counties with Planned Parenthood affiliates but increased from $54.9 \%$ to $58.5 \%$ in the counties without such affiliates (estimated difference in differences in counties with affiliates as compared with those without affiliates, -22.9 percentage points; $\mathrm{P}<0.001$ ). During this period in counties with Planned Parenthood affiliates, the rate of childbirth covered by Medicaid increased by 1.9 percentage points (a relative increase of $27.1 \%$ from baseline) within 18 months after the claim $(\mathrm{P}=0.01)$.

\section{CONCLUSIONS}

The exclusion of Planned Parenthood affiliates from a state-funded replacement for a Medicaid fee-for-service program in Texas was associated with adverse changes in the provision of contraception. For women using injectable contraceptives, there was a reduction in the rate of contraceptive continuation and an increase in the rate of childbirth covered by Medicaid. (Funded by the Susan T. Buffett Foundation.)

From the Population Research Center, University of Texas at Austin (A.J.S., J.E.P.), the Texas Health and Human Services Commission (I.M.F.-V., R.L.A.), and Graves, Dougherty, Hearon, and Moody (P.S.) - all in Austin, TX. Address reprint requests to Dr. Potter at the Population Research Center, University of Texas at Austin, 305 East 23rd St., Stop G1800, Austin, TX 78712-1699, or at joe@prc .utexas.edu.

This article was published on February 3 , 2016, at NEJM.org.

N Engl J Med 2016;374:853-60. DOI: 10.1056/NEJMsal511902 Copyright (c) 2016 Massachusetts Medical Society. 
F EDERAL PUBLIC HEALTH FINANCING through Medicare, Medicaid, and the Affordable Care Act relies on an array of public and private entities to deliver health care services. Historically, federal statute or rule has required that all medically qualified providers be eligible to provide care that is funded wholly or in part through federal programs. Legislation challenging this tradition by the exclusion of Planned Parenthood affiliates from participation in stateadministered, federally funded family-planning programs has been adopted or proposed in 17 states and both houses of the U.S. Congress. ${ }^{1}$ Texas was the first state to enforce such a law.

Beginning in 2007, Texas operated a Medicaid waiver program, the Women's Health Program, with $90 \%$ of funding from the federal government. ${ }^{2}$ In 2011, the Texas legislature directed the program to exclude Planned Parenthood affiliates. The federal Centers for Medicare and Medicaid Services informed Texas that because the exclusion of medically qualified providers violated federal law, it would not renew the waiver but would continue transition funding through the end of 2012. Litigation kept Planned Parenthood affiliates functioning in the program until the transition funding ended. Texas then replaced the federally funded program with a nearly identical $100 \%$ state-funded program (the Texas Women's Health Program) that excluded clinics affiliated with an abortion provider, effective January 1, 2013. ${ }^{3}$

Effective 15 months earlier (on September 1, 2011), Texas had cut family-planning grants (a separate funding stream) by $66 \%$ and redistributed the remaining grant funding away from dedicated family-planning providers, such as, but not limited to, Planned Parenthood affiliates. The Texas legislature did this by removing Title $\mathrm{V}$ and Title XX family-planning funding and requiring the initiation of a new, tiered grant-award process favoring county health departments, community health centers, and other comprehensive care providers. ${ }^{4}$ The 2011 reductions in grants and redistribution of funds were followed by the closure of 82 family-planning clinics, about a third of which were affiliated with Planned Parenthood. ${ }^{5}$ This sharp curtailment of the family-planning safety net in Texas occurred before the 2013 exclusion of Planned Parenthood affiliates from the fee-for-service family-planning program.

We used claims data for all clients of the
Women's Health Program and its replacement, the Texas Women's Health Program, to assess changes in the provision of contraceptives after the exclusion of Planned Parenthood affiliates. Among women who use injectable contraception (depot medroxyprogesterone acetate), we also estimated the change in continuation of the contraceptive method in the program and in the rate of childbirth covered by Medicaid after the exclusion.

METHODS

\section{DATA SOURCES}

Our data included all pharmacy and medical claims from January 1, 2011, to December 31, 2014, under public fee-for-service family-planning insurance programs in Texas. We also accessed all claims for childbirth covered by Medicaid using unique identifications for two cohorts of women who use injectable contraceptives. We retrieved data regarding women's counties of residence from the eligibility and billing system. We also used administrative records from the Texas Department of State Health Services and from Planned Parenthood to categorize counties as either having or not having providers affiliated with Planned Parenthood at the beginning of the study.

In keeping with the eligibility criteria of the programs, all women who were receiving services were fertile, legal Texas residents between the ages of 18 and 44 years with incomes at or below $185 \%$ of the federal poverty level. Using billing records, we identified the women on the basis of the presence of a medical claim that included one or more of the Current Procedural Terminology codes for a valid family-planning service or a pharmacy claim that included an appropriate national pharmacy code for a contraceptive method. For each quarter, we categorized contraceptive methods into three groups: long-acting reversible contraceptives (LARC; contraceptive implants and intrauterine devices), an injectable contraceptive (depot medroxyprogesterone acetate), and short-acting hormonal methods (oral contraceptive pills, transdermal contraceptive patches, and contraceptive rings). We then separated each set of claims into those that were filed in counties that had a Planned Parenthood affiliate in 2011 and those that were filed in counties without such an affiliate at that time.

Of the 254 counties in Texas, only 23 had 
clinics affiliated with Planned Parenthood. We first compared the group of counties that had a Planned Parenthood-affiliated clinic with those that did not with respect to the number of women between the ages of 18 and 44 years who had household incomes that would qualify them for the program $(\leq 185 \%$ of the federal poverty level), the number of childbirths to legal residents covered by Medicaid, and the proportion of women between the ages of 18 and 44 years who did not have health insurance. We obtained these indicators from the American Community Survey, using 5-year averages centered on 2012, and from Texas Medicaid billing records. ${ }^{6}$

We also assessed the quarterly volume of program claims for contraceptives, according to method, for counties with Planned Parenthood affiliates and those without such affiliates during the 16 observed quarters ( 8 before and 8 after the exclusion). Among women using an injectable contraceptive in counties with Planned Parenthood affiliates and those without such affiliates in the fourth quarters of 2011 and 2012, we also measured the proportion of women who returned to the program for any service, who returned for an on-time subsequent injection, and who underwent childbirth covered by Medicaid during the following 18 months.

\section{STUDY OVERSIGHT}

The institutional review board at the University of Texas at Austin determined that the study was exempt from human-subjects review; therefore, no informed consent was required. The authors designed the study, and the funder had no role in the analysis or interpretation of the data, the writing of the manuscript, or the decision to submit the manuscript for publication. All the authors vouch for the integrity and completeness of the data and analyses.

\section{STATISTICAL ANALYSIS}

We used the difference-in-differences method and regression discontinuity to compare the number of claims for each contraceptive method in counties with Planned Parenthood affiliates and in those without such affiliates before and after the exclusion on January 1, 2013. This approach accounted for the influence of timeinvariant differences between counties with affiliates and those without affiliates and for statewide trends over time that could influence service provision. ${ }^{?}$
On the basis of the quarterly number of claims for each contraceptive method, we calculated the difference in provision between counties with Planned Parenthood affiliates and those without such affiliates for each quarter and each method. We fitted local linear regression models to summarize the differences in volumes for each method. ${ }^{8}$ In these models, we allowed the slopes and intercepts to vary before and after the exclusion by using an indicator that was equal to 1 after the exclusion and 0 before the exclusion and an interaction between this indicator and time. We estimated the discontinuity in the differences at the point of the exclusion with the indicator for post-exclusion. Finally, we computed the relative change in provision by dividing this discontinuity by the estimated provision in counties with Planned Parenthood affiliates at the point of exclusion (as estimated by means of linear regression).

In order to assess changes in the rates of contraceptive continuation and subsequent childbirth covered by Medicaid associated with the exclusion of Planned Parenthood affiliates, we focused on women who were using an injectable contraceptive. Unlike other forms of contraception, this method requires regular provider visits and has a relatively short span of contraceptive effectiveness ( 3 months). These features of the method allowed us to observe changes in the rate of childbirth within 18 months after the claim, which would not be possible with LARC methods (which last longer) or oral contraceptive pills (which may be dispensed for a single month or up to 12 months per claim).

We included two cohorts in our comparison. The first cohort received an injection in the fourth quarter of 2011 and thus had a year to continue receiving services before the exclusion of Planned Parenthood affiliates took effect. The second cohort received an injection in the fourth quarter of 2012 and thus was subject to the influence of the exclusion before the due date for the next injection. For each cohort and county group, we computed the proportions of women who received a service covered by the program in the following quarter, who received an injection in that quarter, and who underwent childbirth covered by Medicaid in the following 18 months. We calculated the difference in differences between the two cohorts and groups of counties.

In order to determine the probability that 


\begin{tabular}{|c|c|c|}
\hline Characteristic & $\begin{array}{c}\text { Counties with } \\
\text { Planned Parenthood } \\
\text { Affiliates }\end{array}$ & $\begin{array}{c}\text { Counties without } \\
\text { Planned Parenthood } \\
\text { Affiliates }\end{array}$ \\
\hline No. of Texas counties & 23 & 231 \\
\hline No. of women between the ages of 18 and $44 \mathrm{yr} *$ & $1,071,000$ & 708,000 \\
\hline $\begin{array}{l}\text { Women between the ages of } 18 \text { and } 44 \mathrm{yr} \text { without health insurance } \\
\qquad \begin{array}{c}-\end{array}\end{array}$ & 33 & 34 \\
\hline No. of childbirths covered by Medicaid in $2012 \%$ & 97,075 & 58,198 \\
\hline Closures of family-planning clinics $2011-2013$ - no./total no. (\%) $\mathbb{~}$ & $33 / 194(17)$ & $49 / 167(29)$ \\
\hline
\end{tabular}

* All the women included in the study had an income at or below $185 \%$ of the federal poverty level.

$\uparrow$ The percentages are based on 2010-2014 American Community Survey summary files.

Data are from Medicaid claims records, which apply only to documented residents.

$\int$ Data are from the Texas Policy Evaluation Project. ${ }^{5}$

women would return to the program during the next quarter, would receive an on-time subsequent injection, and would undergo childbirth covered by Medicaid within 18 months, we used generalized linear models for the response frequencies in the respective tables. In each model, we used an indicator equal to 1 after the exclusion and 0 before the exclusion, an indicator equal to 1 for the group of counties with Planned Parenthood affiliates and 0 for those without Planned Parenthood affiliates, and an interaction between these indicators to provide a direct statistical test of the difference in differences in the probability of each outcome. The assumed distribution of the frequencies (either binomial or Poisson) did not substantially change the significance of the tests. We report $\mathrm{P}$ values from the Poisson models because they were larger and thus more conservative.

\section{RESULTS}

\section{CHANGE IN CLAIMS FOR CONTRACEPTIVES}

The 23 counties with Planned Parenthood affiliates were home to $60 \%$ of female Texas residents between the ages of 18 and 44 years who were living at or below $185 \%$ of the federal poverty level (Table 1). The proportions of women who had no health insurance were similar in counties with Planned Parenthood affiliates and in those without such affiliates. Of all the childbirths that legal residents underwent and that were covered by Medicaid in 2012, a total of 63\% occurred in counties with Planned Parenthood affiliates. In the period before the exclusion, there were 82 closures of family-planning clinics in
Texas, ${ }^{5}$ and the decrease in the number of family-planning clinics was greater in counties without Planned Parenthood affiliates than in those with such affiliates.

Before the exclusion, the numbers of claims for LARC methods and injectable contraceptives were decreasing in both groups of counties, with somewhat sharper decreases in those with Planned Parenthood affiliates (Fig. 1A). However, the number of claims for short-acting hormonal methods was increasing in both groups of counties during the eight quarters before the exclusion.

In the quarter after the exclusion, there was a sharp decrease in the number of claims for

Figure 1 (facing page). Quarterly Claims for Contraceptives, According to Method, Type of County, and Timing before or after the Exclusion of Planned Parenthood Affiliates.

Panel A shows the quarterly number of claims for longacting reversible contraceptive (LARC) methods, injectable agents, and short-acting hormonal methods, according to whether the woman's county of residence had Planned Parenthood affiliates before the exclusion of such affiliates from the Texas Women's Health Programs as of January 1, 2013. Panel B shows the difference in the number of such claims between the group of counties that had a Planned Parenthood affiliate and the group that did not during the same period before and after the exclusion. Lines that are fitted to local linear regression models show the differences in volumes for each method; dashed lines indicate $95 \%$ confidence intervals. The change in the difference at the point of the exclusion was significant with respect to the provision of LARC methods and injectable contraceptives ( $P<0.001$ for both comparisons) but not with respect to short-acting hormonal methods $(P=0.22)$. 
LARC methods in counties with Planned Parenthood affiliates but not in those without such affiliates. In subsequent quarters, the number of claims for LARC methods increased in both groups of counties. After the exclusion, the pro- vision of injectable contraceptives fell sharply in counties with Planned Parenthood affiliates but not in counties without such affiliates; subsequently, the numbers of claims in both groups of counties remained relatively stable during the

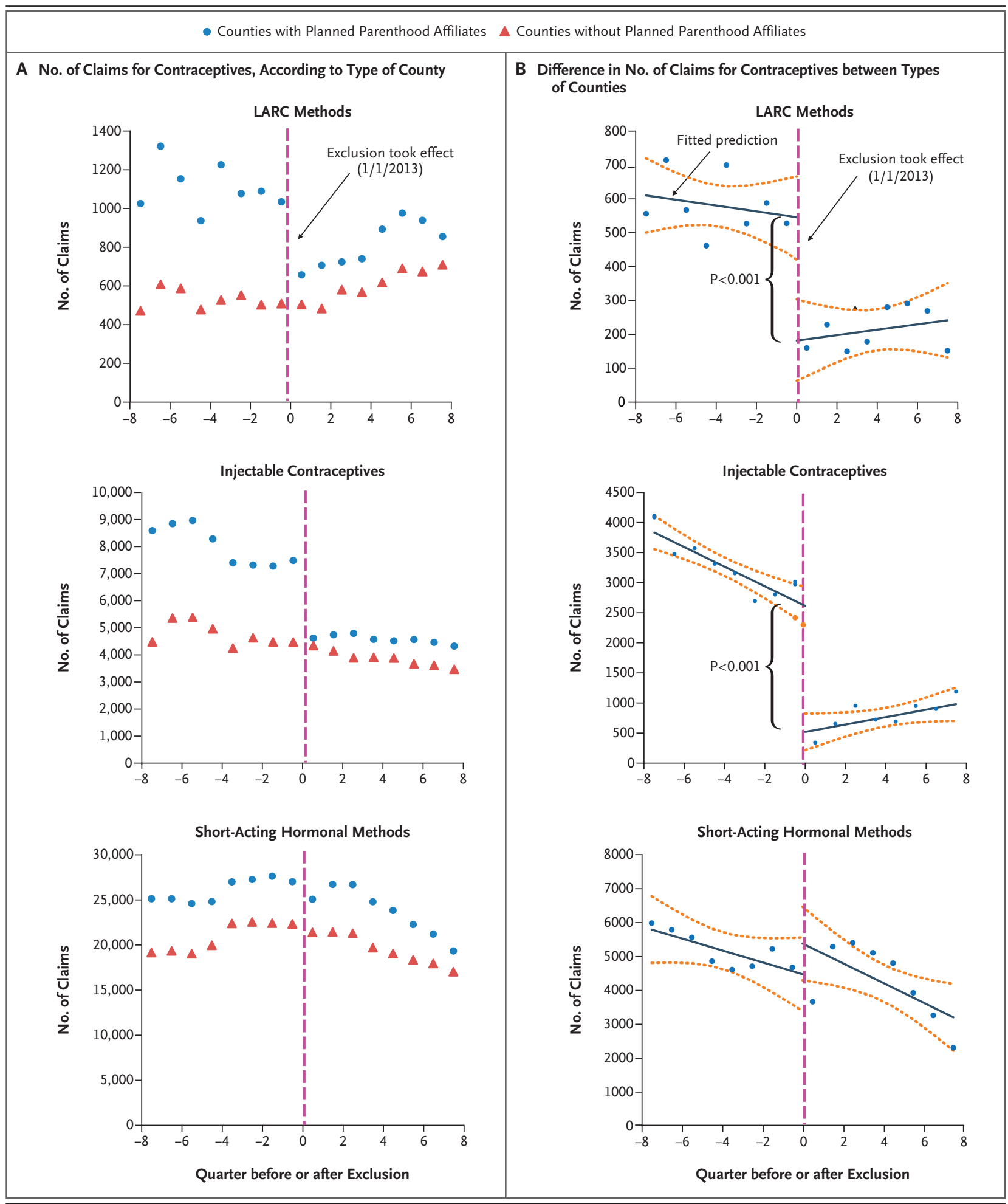


next 2 years. In contrast, the provision of shortacting hormonal methods changed little in the two groups of counties in the quarter after the exclusion and declined steadily thereafter.

The difference in the number of claims for each type of contraceptive in each quarter in counties with Planned Parenthood affiliates and in those without such affiliates is shown in Figure 1B. The difference in differences at the point of Planned Parenthood exclusion was significant for the provision of LARC methods and injectable contraceptives $(\mathrm{P}<0.001$ for both comparisons) but not for short-acting hormonal methods $(\mathrm{P}=0.22)$. The exclusion of Planned Parenthood affiliates was associated with estimated reductions in the number of claims from 1042 to 672 (relative reduction, 35.5\%) for LARC methods and from 6832 to 4708 (relative reduction, 31.1\%) for injectable contraceptives.

\section{CHANGE IN RATES OF CONTRACEPTIVE CONTINUATION AND CHILDBIRTH}

Table 2 provides a comparison of the rates of continuation of contraception and of childbirth covered by Medicaid between women who received a contraceptive injection in the fourth quarter of 2011 and those who received such an injection in the fourth quarter of 2012. The proportion of women returning for a subsequent on-time contraceptive injection in counties with Planned Parenthood affiliates was lower after the exclusion. Specifically, the percentage of women decreased from $56.9 \%$ to $37.7 \%$ in counties with Planned Parenthood affiliates but increased from $54.9 \%$ to $58.5 \%$ in counties without such affiliates (estimated difference in differences for counties with affiliates as compared with those without affiliates, -22.9 percentage points; $\mathrm{P}<0.001)$. This change represents a relative decrease of $40.2 \%$ from baseline $(-22.9$ percentage points divided by $56.9 \%$ ).

The exclusion was also associated with an increased rate of childbirth covered by Medicaid within 18 months after the claim. The percentage of women who underwent childbirth covered by Medicaid within 18 months increased from $7.0 \%$ to $8.4 \%$ in the counties with Planned Parenthood affiliates and decreased from $6.4 \%$ to $5.9 \%$ in the counties without Planned Parenthood affiliates (estimated difference in differences, 1.9 percentage points; $\mathrm{P}=0.01$ ). This change represents a relative increase of $27.1 \%$ from baseline (1.9 percentage points divided by $7.0 \%$ ) in the proportion of women using injectable contraceptives who underwent childbirth covered by Medicaid within 18 months after the claim.

\section{DISCUSSION}

After Texas abruptly excluded Planned Parenthood affiliates from its fee-for-service familyplanning program, the number of claims for LARC methods declined, as did the number of claims for contraceptive injections. Among women using injectable contraceptives, fewer women who received an injection in the quarter preceding the exclusion continued to receive an injection through the program than did those in an earlier cohort. In addition, there was a disproportionate increase in the rate of childbirth covered by Medicaid. Although data are lacking on intendedness of pregnancy, it is likely that many of these pregnancies were unintended, since the rates of childbirth among these women increased in the counties that were affected by the exclusion and decreased in the rest of the state.

The reduction in the number of claims for LARC methods in the counties with Planned Parenthood affiliates at the time of the exclusion represents a divergence from the trend toward an increased number of claims for LARC methods in counties with Planned Parenthood affiliates in the years preceding the exclusion, a trend that has also been observed nationally. ${ }^{9,10}$ This change is worrisome, since increased access to LARC methods is a priority of the American College of Obstetricians and Gynecologists, ${ }^{11}$ and one study has indicated substantial unmet demand for LARC methods in Texas. ${ }^{12}$ Thus, the introduction of additional barriers to access to LARC methods by the exclusion of skilled, specialized family-planning providers was associated with a shift toward methods that have lower rates of efficacy and continuation ${ }^{13}$ and, in the case of women who used injectable contraceptives in the fourth quarter of 2012, an increase in the rate of childbirth covered by Medicaid.

Our data are observational and cannot prove causality. However, our analyses suggest that the exclusion of Planned Parenthood affiliates from the Texas Women's Health Program had an adverse effect on low-income women in Texas by 
reducing the provision of highly effective methods of contraception, interrupting contraceptive continuation, and increasing the rate of childbirth covered by Medicaid. Although our data do not capture specific barriers that Planned Parenthood clients encountered after the exclusion, another study that was based on interviews with women using injectable contraceptives that were paid for by the Women's Health Program before the exclusion of Planned Parenthood affiliates in two Texas cities (Houston and Midland) revealed obstacles that these clients faced after the exclusion. Clients who returned to Planned Parenthood after the exclusion were required to pay a fee of $\$ 60$ or more for a contraceptive injection. ${ }^{14}$ Those who sought a new provider were often required to undergo additional examinations or office visits or were charged a copayment before receiving the injection.

One limitation of our analysis is that the effect that we observed was restricted to the 2 years immediately after the exclusion. The slope of the local regression lines that were fit to the provision of contraceptives after the exclusion suggests an attenuation of changes over time, as has been observed in other studies of the effects of changes in reproductive health policy. ${ }^{15}$ In addition, our models have not been adjusted for any changes in county-level characteristics that may have taken place during the period of observation. Another limitation is that we have no information on contraceptive services that women paid for out of pocket or received through other subsidized programs. However, since the fee-forservice family-planning program was the payer of first resort and since funding for subsidized family planning was severely limited in Texas during the study period, ${ }^{5}$ it is unlikely that women were pulled away from the Texas Women's Health Program to be served through other programs. Also, our analysis includes only childbirths covered by Medicaid in Texas, and data for women who gave birth out of state or with private insurance coverage are not captured.

Before the Planned Parenthood exclusion, cuts in grant funding and the reduced priority given to specialized clinics had already substantially reduced the amount of funding available to Planned Parenthood affiliates and reduced access to LARC methods, especially among women who did not qualify for the Medicaid waiver family-planning program because of their resi-

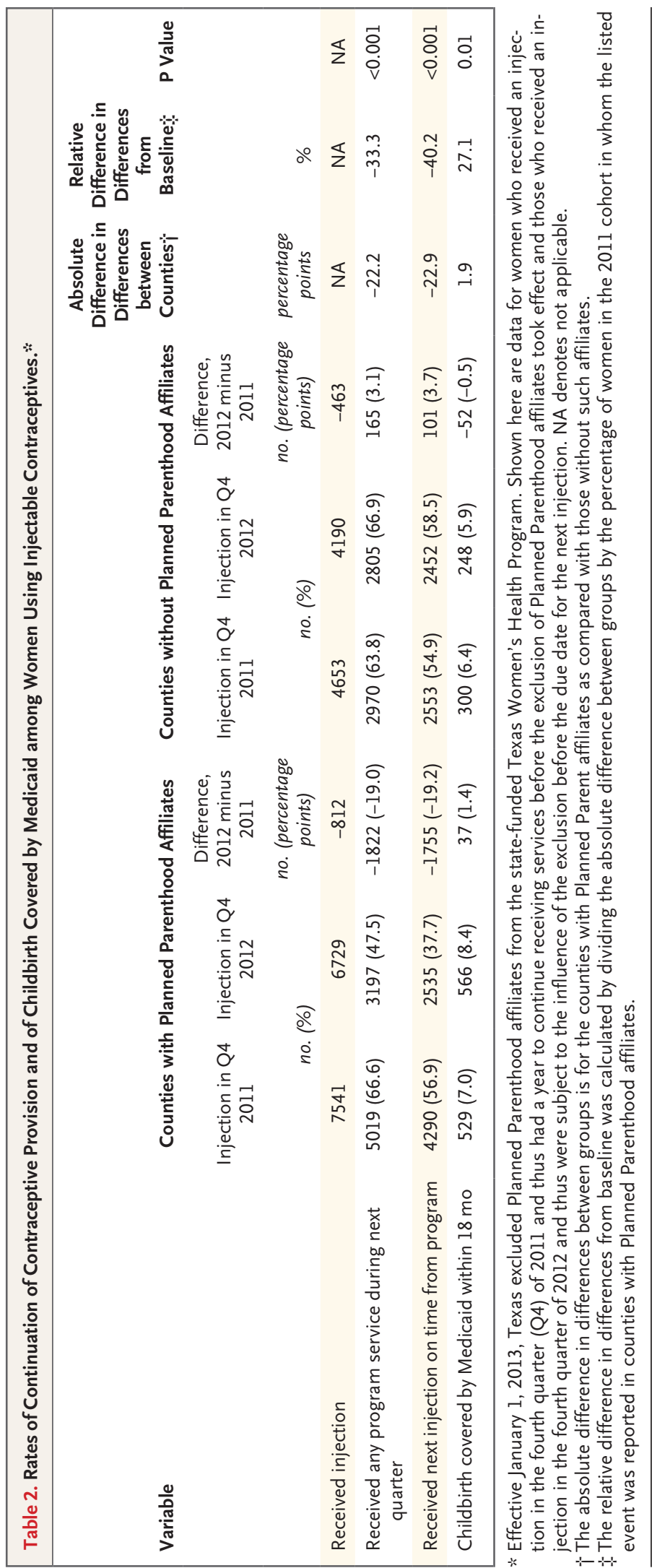


dency status. ${ }^{5}$ Thus, it is likely that the changes we observed in the fee-for-service family-planning program after the Planned Parenthood exclusion represent only a portion of the total reduction in the availability of services associated with the multiple efforts to defund these providers. Moreover, because the Texas family-planning safety net includes a diverse mix of Planned Parenthood affiliates, private dedicated familyplanning providers, and public entities ${ }^{4,5}$ our estimates may be conservative if they are applied to states in which Planned Parenthood affiliates are a more dominant source of family-planning care.

In conclusion, the implementation of the 2013 exclusion of Planned Parenthood affiliates from a Medicaid waiver program in Texas was associ- ated with adverse changes in the rates of provision and continuation of contraception and with increases in the rate of childbirth covered by Medicaid. These findings have implications regarding the likely consequences of proposals to exclude Planned Parenthood affiliates from public funding in other states or at the national level.

The views expressed in this article are those of the authors and do not necessarily represent the views or policies of the Texas Health and Human Services Commission

Supported by a grant from the Susan T. Buffett Foundation for the Texas Policy Evaluation Project and a grant (R24-042849) from the Eunice Kennedy Shriver National Institute of Child Health and Human Development to the Population Research Center, University of Texas at Austin.

Disclosure forms provided by the authors are available with the full text of this article at NEJM.org.

We thank Daniel Grossman, M.D., and Daniel Powers, Ph.D., for their helpful comments on earlier drafts of the manuscript.

\section{REFERENCES}

1. Medicaid family planning eligibility expansions. New York: Guttmacher Institute, January 2016 (http://www.guttmacher .org/statecenter/spibs/spib_SMFPE.pdf).

2. Aday LA, Andersen R. A framework for the study of access to medical care. Health Serv Res 1974;9:208-20.

3. Texas Department of State Health Services v. Balquinta. 429 S.W.3d 726, 730 735 (Tex. App.-Austin 2014, rev. dism'd); 2014.

4. White K, Grossman D, Hopkins K, Potter JE. Cutting family planning in Texas. N Engl J Med 2012;367:1179-81.

5. White K, Hopkins K, Aiken AR, et al. The impact of reproductive health legislation on family planning clinic services in Texas. Am J Public Health 2015;105:851-8. 6. U.S. Census Bureau. American Community Survey. 2015 (http://www.census .gov/data/developers/data-sets/acs-survey -5-year-data.html).
7. Dimick JB, Ryan AM. Methods for evaluating changes in health care policy: the difference-in-differences approach. JAMA 2014;312:2401-2.

8. Imbens GW, Lemieux T. Regression discontinuity designs: a guide to practice. J Econom 2008;142:615-35.

9. Finer LB, Jerman J, Kavanaugh ML. Changes in use of long-acting contraceptive methods in the United States, 20072009. Fertil Steril 2012;98:893-7.

10. Kavanaugh ML, Jerman J, Finer LB. Changes in use of long-acting reversible contraceptive methods among U.S. women, 2009-2012. Obstet Gynecol 2015;126: 917-27.

11. American College of Obstetricians and Gynecologists Committee on Gynecologic Practice, Long-Acting Reversible Contraception Working Group. ACOG Committee Opinion no. 450: increasing use of contraceptive implants and intra- uterine devices to reduce unintended pregnancy. Obstet Gynecol 2009;114:1434-8. 12. Potter JE, Hopkins K, Aiken AR, et al. Unmet demand for highly effective postpartum contraception in Texas. Contraception 2014;90:488-95.

13. Trussell J, Guthrie K. Choosing a contraceptive: safety, efficacy and personal considerations. In: Hatcher RA, Trussell J, Nelson AL, Cates W, Kowal D, eds. Contraceptive technology. 12th ed. New York: Ardent Media, 2011:45-74.

14. Woo CJ, Alamgir H, Potter JE. Women's experiences after Planned Parenthood's exclusion from a family planning program in Texas. Contraception 2015 December 8 (Epub ahead of print).

15. Colman S, Joyce T. Regulating abortion: impact on patients and providers in Texas. J Policy Anal Manage 2011;30:77597.

Copyright (c) 2016 Massachusetts Medical Society. 